\title{
Susceptibility to fluconazole of Candida clinical isolates determined by FUN-1 staining with flow cytometry and epifluorescence microscopy
}

\author{
CIDÁLIA PINA-VAZ*††, FILIPE SANSONETTY†, ACÁCIO G. RODRIGUES*†, \\ SOFIA COSTA-DE-OLIVEIRA*, J. MARTINEZ-DE-OLIVEIRA§ and ANTÓNIO F. FONSECA*
}

* Department of Microbiology, Porto School of Medicine, University of Porto, ${ }^{\dagger}$ Institute of Pathology and Molecular Immunology of Porto University, \$Institute of Molecular and Cell Biology of Porto University and $\S$ Department of Gynecology, Porto School of Medicine, Porto, Portugal

\begin{abstract}
The susceptibility of clinical Candida isolates to fluconazole was assayed by flow cytometry (FCM) and epifluorescence microscopy (EFM), with FUN-1 staining. In all, 25 clinical isolates of Candida spp. (12 sensitive, 3 dose-dependently sensitive and 10 resistant to fluconazole according to the NCCLS M27-A protocol) were treated with increasing concentrations of fluconazole during 1 or $2 \mathrm{~h}$ staining with FUN-1 for 30 min and analysed, respectively, by FCM at $575 \mathrm{~nm}$ (FL2) and by EFM. Fluconazolesusceptible strains showed an increased accumulation of FUN-1 in comparison with controls as determined by FCM and a reduced metabolic processing of the probe, confirmed by EFM. Conversely, resistant strains showed decreased FUN-1 staining and were able to process the probe. The fluconazole minimal inhibitory concentrations (MICs) determined by FCM or EFM after FUN-1 staining compared very well with the corresponding values determined by the M27-A protocol, indicating that FUN-1 staining can be used as an alternative to the conventional method. MIC values of resistant strains, with the exception of $C$. $k$ rusei, were lower when treatment with fluconazole followed pre-incubation with $0.1 \mathrm{mM}$ sodium azide, a concentration known to inhibit the activity of efflux pumps. These results show that FUN-1 staining can be used as an alternative and rapid method for the assessment of susceptibility of Candida clinical isolates to fluconazole. Furthermore, the results suggest that resistance of Candida cells to fluconazole, with the exception of $C$. krusei strains, is likely to be due to the activity of efflux pumps.
\end{abstract}

\section{Introduction}

An increase in human fungal infections, particularly in immunocompromised patients and in those admitted to intensive care units, has been seen in recent years, and there has been growing resistance to antifungal agents [1]. The need to predict the outcome of antifungal therapy based upon in-vitro results has encouraged the search for improved methods for antifungal susceptibility testing that would overcome the problems related to conventional methods [2].

Azoles are currently the most widely used class of

Received 26 May 2000; revised version accepted 14 Oct. 2000.

Corresponding author: Dr C. Pina-Vaz (e-mail: micfam@, ip.pt). antifungal agents. Because of its high oral bioavailability and safety profile [3], fluconazole has become the drug of choice for treatment of most common AIDS-associated opportunist fungal infections, such as oropharyngeal and other mucosal manifestations of candidosis.

The aim of the present study was to develop methods that in a short period of time would allow the evaluation of susceptibility of Candida isolates to fluconazole. FUN-1 has been used as an indicator of metabolic vitality in yeast cells [4]. In metabolically active cells, FUN-1 (a membrane-permeant fluorescent probe) is converted into orange/red cylindrical intravacuolar structures (CIVS) that are best detected by epifluorescence microscopy (EFM) [4]. In contrast, yeast cells with impaired metabolism do not form CIVS; the dye remains in the cytoplasm in a diffuse pattern, which can be detected by an increase in 
intracellular green-yellow fluorescence by flow cytometry (FCM) [4].

This study used both approaches to investigate the effect of fluconazole on Candida isolates. The MIC values with FCM and EFM after FUN-1 staining were compared with those obtained with the conventional NCCLS protocol M27-A [5].

\section{Materials and methods}

\section{Candida isolates}

A total of 25 clinical isolates of Candida spp. was studied (Table 1); they were classified as sensitive (S, 12 isolates), susceptible dose-dependent (S-DD, 3 isolates) or resistant ( $\mathrm{R}, 10$ isolates) to fluconazole, in accordance with MIC values determined as described below (M27-A protocol). The yeasts were kept in Brain-Heart Broth (Difco Laboratories, Detroit, MI, USA) with glycerol $5 \%$ at $-70^{\circ} \mathrm{C}$ until tested. For each experiment, the yeasts were subcultured twice on Sabouraud agar (Difco) for $24 \mathrm{~h}$ at $35^{\circ} \mathrm{C}$, and suspensions of blastoconidia were prepared in saline at a cell density of $\left(1 \times 10^{6}\right)-\left(5 \times 10^{6}\right)$ cells $/ \mathrm{ml}$.

\section{Antifungal agent}

Fluconazole was purchased from Pfizer (Groton, CT, USA) and maintained as a stock solution at $-70^{\circ} \mathrm{C}$ until used.

\section{Determination of fluconazole MIC according to NCCLS M27-A}

MIC values were determined by a macro-dilution test according to the NCCLS reference method (M27-A protocol) [5]. The MIC was regarded as the lowest concentration of fluconazole that substantially inhibited growth (>80\%). C. albicans ATCC 90028 and $C$. krusei ATCC 6258 were included as control strains.

\section{Treatment with fluconazole for FCM and EFM}

Candida blastoconidia suspended in saline were centrifuged and resuspended in phosphate-buffered saline (PBS, pH 7.0) supplemented with glucose $2 \%$. The cell concentration was adjusted to $1 \times 10^{6}$ cells/ml with a haemocytometer.

In a preliminary assay, three $\mathrm{S}$ strains (H50, M9, SCO), one S-DD strain (M44) and three R strains (H58, H29, H11) were incubated with different concentrations of fluconazole $(1,4,16,32$ and $64 \mathrm{mg} / \mathrm{L})$, stained with FUN-1 and analysed both by FCM and EFM after 30, 60 and $120 \mathrm{~min}$. Incubation with the antifungal agent was done at $35^{\circ} \mathrm{C}$ with shaking (200 strokes $/ \mathrm{min}$ ). As a control, yeast cells were incubated under similar conditions in the absence of fluconazole.

In the final assay, the 25 yeast isolates listed in Table 1 were treated with fluconazole $(1,4,16$ and $32 \mathrm{mg} / \mathrm{L})$

Table 1. Candida isolates studied, MIC values $(\mathrm{mg} / \mathrm{L})$ and phenotypes determined by the NCCLS M27-A protocol and by flow cytometry (FCM)

\begin{tabular}{|c|c|c|c|c|c|c|c|c|}
\hline \multirow[b]{2}{*}{ Isolate } & \multirow[b]{2}{*}{ MIC M27-A } & \multirow[b]{2}{*}{ Phenotype M27-A } & \multicolumn{4}{|c|}{ SI at fluconazole concentration $(\mathrm{mg} / \mathrm{L})$} & \multirow[b]{2}{*}{ MIC FCM } & \multirow[b]{2}{*}{ Phenotype FCM } \\
\hline & & & 1 & 4 & 16 & 32 & & \\
\hline C. krusei $\mathrm{H} 29$ & $>64$ & $\mathrm{R}$ & 0.85 & 0.87 & 0.90 & 0.91 & $>32$ & $\mathrm{R}$ \\
\hline C. krusei $\mathrm{H} 32$ & $>64$ & $\mathrm{R}$ & 0.64 & 0.60 & 0.54 & 0.68 & $>32$ & $\mathrm{R}$ \\
\hline C. krusei $\mathrm{H} 11$ & $>64$ & $\mathrm{R}$ & 0.99 & 0.99 & 0.91 & 0.97 & $>32$ & $\mathrm{R}$ \\
\hline C. krusei H9 & $>64$ & $\mathrm{R}$ & 0.86 & 0.86 & 0.73 & 0.84 & $>32$ & $\mathrm{R}$ \\
\hline C. albicans M36 & 64 & $\mathrm{R}$ & 0.60 & 0.65 & 0.72 & 0.71 & $>32$ & $\mathrm{R}$ \\
\hline C. albicans H37 & $>64$ & $\mathrm{R}$ & 0.85 & 0.75 & 0.74 & 0.71 & $>32$ & $\mathrm{R}$ \\
\hline C. albicans $\mathrm{H} 65$ & $>64$ & $\mathrm{R}$ & 0.83 & 0.78 & 0.76 & 0.74 & $>32$ & $\mathrm{R}$ \\
\hline C. albicans H66 & $>64$ & $\mathrm{R}$ & 0.94 & 0.90 & 0.90 & 0.96 & $>32$ & $\mathrm{R}$ \\
\hline C. albicans H58 & $>64$ & $\mathrm{R}$ & 0.98 & 0.97 & 0.85 & 0.79 & $>32$ & $\mathrm{R}$ \\
\hline C. glabrata $\mathrm{H} 30$ & $>64$ & $\mathrm{R}$ & 0.98 & 0.98 & 0.99 & 0.99 & $>32$ & $\mathrm{R}$ \\
\hline C. glabrata M2 & 16 & S-DD & 0.92 & 0.87 & 0.95 & 1.11 & 32 & S-DD \\
\hline C. albicans SER5 & 16 & S-DD & 0.82 & 0.96 & 1.81 & 2.42 & 16 & S-DD \\
\hline C. albicans M44 & 32 & S-DD & 0.98 & 0.97 & 0.95 & 1.12 & 32 & S-DD \\
\hline C. albicans $\mathrm{H} 33$ & 1 & $\mathrm{~S}$ & 1.05 & 1.08 & 1.13 & 1.24 & 1 & $\mathrm{~S}$ \\
\hline C. albicans SCO & 1 & $\mathrm{~S}$ & 1.04 & 1.06 & 1.12 & 1.14 & 1 & $\mathrm{~S}$ \\
\hline C. albicans SER1 & 1 & $\mathrm{~S}$ & 1.46 & 1.56 & 1.48 & 1.49 & 1 & $\mathrm{~S}$ \\
\hline C. albicans M9 & 1 & $\mathrm{~S}$ & 1.05 & 1.06 & 1.12 & 1.25 & 1 & $\mathrm{~S}$ \\
\hline C. albicans M28 & 2 & $\mathrm{~S}$ & 1.16 & 1.18 & 1.19 & 1.19 & 1 & $\mathrm{~S}$ \\
\hline C. glabrata PALM & 8 & $\mathrm{~S}$ & 1.28 & 1.34 & 1.44 & 1.44 & 1 & $\mathrm{~S}$ \\
\hline C. glabrata $\mathrm{H} 36$ & 4 & $\mathrm{~S}$ & 1.28 & 1.29 & 1.29 & 1.28 & 1 & $\mathrm{~S}$ \\
\hline C. lusitaniae $\mathrm{H} 22$ & 0.25 & $\mathrm{~S}$ & 1.06 & 1.07 & 1.08 & 1.16 & 1 & $\mathrm{~S}$ \\
\hline C. rugosa $\mathrm{H} 10$ & 2 & $\mathrm{~S}$ & 1.23 & 1.30 & 1.31 & 1.39 & 1 & $\mathrm{~S}$ \\
\hline C. guilliermondii MAT24 & 1 & $\mathrm{~S}$ & 1.20 & 1.26 & 1.32 & 1.34 & 1 & $\mathrm{~S}$ \\
\hline C. albicans $\mathrm{H} 38$ & 1 & $\mathrm{~S}$ & 1.04 & 1.06 & 1.33 & 1.35 & 1 & $\mathrm{~S}$ \\
\hline C. lusitaniae $\mathrm{H} 50$ & 1 & $\mathrm{~S}$ & 1.24 & 1.43 & 1.50 & 1.54 & 1 & $\mathrm{~S}$ \\
\hline
\end{tabular}

SI, staining index after incubation with different concentrations of fluconazole. Statistical analysis (Student's $t$ test) for 60 min: comparison of SI values with fluconazole at $1 \mathrm{mg} / \mathrm{L}$ between $\mathrm{R}$ strains (M27-A protocol) and S strains, $\mathrm{p}<0.001$; comparison of SI values with fluconazole at $32 \mathrm{mg} / \mathrm{L}$ between S-DD strains and $\mathrm{S}$ strains, $\mathrm{p}=0.590$ and between $\mathrm{S}-\mathrm{DD}$ strains and $\mathrm{R}$ strains, $\mathrm{p}=0.008$. Data are mean of two independent experiments; no significant differences were found between the results in the two experiments. MICs were determined by the M27-A protocol and by FCM as described in Materials and methods. S, susceptible; R, resistant; S-DD, susceptible dose-dependent. 
for $60 \mathrm{~min}$ for FCM analysis or for $120 \mathrm{~min}$ for EFM analysis.

\section{Staining with FUN-1}

FUN-1 (Molecular Probes Europe BV, Leiden, The Netherlands) staining was optimised, taking into account parameters such as the number of blastoconidia, the concentration of the probe and the duration of incubation.

For FCM, optimal results were obtained with $10^{6}$ blastoconidia/ml stained with $0.5 \mu \mathrm{M}$ FUN-1 in $10 \mathrm{mM}$ sodium HEPES buffer ( $\mathrm{pH}$ 7.2) supplemented with glucose $2 \%$ (GH solution) at $30^{\circ} \mathrm{C}$ for $30 \mathrm{~min}$ and protected from light. As a staining control, the yeast cells were incubated with $1 \mathrm{mM}$ sodium azide for $1 \mathrm{~h}$ before staining with FUN-1. For each isolate, fluorescence of non-treated and non-stained cells (autofluorescence) was also determined. Scattergram analysis and median values of FL2 $(575 \mathrm{~nm})$ were determined with a Coulter XL-MCL flow cytometer (Beckman-Coulter, Hialeah, FL, USA) equipped with a $15-\mathrm{mV}$ argon laser. A total of 30000 cells was analysed.

A staining index (SI) of FUN-1-stained yeast cells was defined as the ratio between the median intensity of fluorescence at FL2 of fluconazole-treated cells and the corresponding value of non-treated suspensions (control). Because active concentrations of fluconazole produced an increase in FUN-1 staining, the MIC determined by FCM was regarded as the lowest concentration of fluconazole that resulted in a SI above that of the control, i.e., SI $>1.00$ after treatment with the antifungal agent.

For EFM optimal results were obtained with $10^{6}$ blastoconidia/ml stained with $1 \mu \mathrm{M} \mathrm{FUN-1}$ at $30^{\circ} \mathrm{C}$ for $30 \mathrm{~min}$ in $\mathrm{GH}$ solution and protected from light. Stained cells were mounted on microscope glass slides with antifading Vectashield Mounting Medium (Vector Laboratories, Burlingane, CA, USA).

A Leitz Laborlux $\mathrm{K}$ microscope (Leica, New York, USA) fitted with a mercury $50 \mathrm{~W}$ lamp, a BP 450-490 $\mathrm{nm}$ excitation filter and an LP $515 \mathrm{~nm}$ emission filter was used. The percentage of yeasts with CIVS was calculated after analysing 200 cells from each suspension. The MIC determined by EFM was regarded as the lowest concentration of fluconazole that resulted in $<50 \%$ of cells showing CIVS after incubation for 120 min with the antifungal agent; the choice of this cut-off point was based on the results shown below (Table 2). FCM and EFM assays were run in duplicate.

\section{Partial energy depletion by sodium azide}

In parallel experiments, Candida cells were partially energy depleted by incubation with $0.1 \mathrm{mM}$ sodium

Table 2. MIC values $(\mathrm{mg} / \mathrm{L})$ and phenotypes determined by the NCCLS M27-A protocol and by epifluorescence microscopy (EFM)

\begin{tabular}{|c|c|c|c|c|c|c|c|c|}
\hline \multirow[b]{2}{*}{ Isolate } & \multirow[b]{2}{*}{ MIC M27-A } & \multirow[b]{2}{*}{ Phenotype M27-A } & \multicolumn{4}{|c|}{$\begin{array}{c}\text { Percent of cells with CIVS at fluconazole } \\
\text { concentration }(\mathrm{mg} / \mathrm{L})\end{array}$} & \multirow[b]{2}{*}{ MIC EFM } & \multirow[b]{2}{*}{ Phenotype EFM } \\
\hline & & & 1 & 4 & 16 & 32 & & \\
\hline C. krusei $\mathrm{H} 29$ & $>64$ & $\mathrm{R}$ & 99.8 & 99.8 & 99.9 & 99.8 & $>32$ & $\mathrm{R}$ \\
\hline C. krusei H32 & $>64$ & $\mathrm{R}$ & 99.5 & 99.5 & 99.2 & 99.0 & $>32$ & $\mathrm{R}$ \\
\hline C. krusei H11 & $>64$ & $\mathrm{R}$ & 99.5 & 99.7 & 99.5 & 99.6 & $>32$ & $\mathrm{R}$ \\
\hline C. krusei H9 & $>64$ & $\mathrm{R}$ & 99.5 & 99.5 & 99.2 & 97.9 & $>32$ & $\mathrm{R}$ \\
\hline C. albicans M36 & 64 & $\mathrm{R}$ & 99.5 & 99.5 & 98.2 & 97.9 & $>32$ & $\mathrm{R}$ \\
\hline C. albicans H37 & $>64$ & $\mathrm{R}$ & 99.1 & 99.5 & 99.7 & 99.2 & $>32$ & $\mathrm{R}$ \\
\hline C. albicans $\mathrm{H} 65$ & $>64$ & $\mathrm{R}$ & 99.2 & 99.9 & 99.3 & 98.7 & $>32$ & $\mathrm{R}$ \\
\hline C. albicans H66 & $>64$ & $\mathrm{R}$ & 99.6 & 99.6 & 98.7 & 98.5 & $>32$ & $\mathrm{R}$ \\
\hline C. albicans H58 & $>64$ & $\mathrm{R}$ & 95.5 & 96.6 & 96.1 & 96.0 & $>32$ & $\mathrm{R}$ \\
\hline C. glabrata $\mathrm{H} 30$ & $>64$ & $\mathrm{R}$ & 99.5 & 99.4 & 99.1 & 98.5 & $>32$ & $\mathrm{R}$ \\
\hline C. glabrata M2 & 16 & S-DD & 99.2 & 95.1 & 92.5 & 45.5 & 32 & S-DD \\
\hline C. albicans SER5 & 16 & S-DD & 99.5 & 92.7 & 85.1 & 41.5 & 32 & S-DD \\
\hline C. albicans M44 & 32 & S-DD & 98.2 & 65.2 & 55.5 & 48.5 & 32 & S-DD \\
\hline C. albicans H33 & 1 & $\mathrm{~S}$ & 8.5 & 6.5 & 3.2 & 0 & 1 & $\mathrm{~S}$ \\
\hline C. albicans SCO & 1 & $\mathrm{~S}$ & 9.1 & 6.2 & 5.3 & 2.1 & 1 & $\mathrm{~S}$ \\
\hline C. albicans SER1 & 1 & $\mathrm{~S}$ & 6.5 & 5.5 & 4.1 & 1.8 & 1 & $\mathrm{~S}$ \\
\hline C. albicans M9 & 1 & $\mathrm{~S}$ & 7.8 & 6.4 & 5.1 & 0.7 & 1 & $\mathrm{~S}$ \\
\hline C. albicans M28 & 2 & $\mathrm{~S}$ & 15.5 & 4.2 & 3.1 & 0 & 1 & $\mathrm{~S}$ \\
\hline C. glabrata PALM & 8 & $\mathrm{~S}$ & 18.5 & 8.5 & 7.1 & 3.2 & 1 & $\mathrm{~S}$ \\
\hline C. glabrata $\mathrm{H} 36$ & 4 & $\mathrm{~S}$ & 19.7 & 11.5 & 3.1 & 0 & 1 & $\mathrm{~S}$ \\
\hline C. lusitaniae $\mathrm{H} 22$ & 0.25 & $\mathrm{~S}$ & 7.5 & 5.2 & 2.4 & 0 & 1 & $\mathrm{~S}$ \\
\hline C. rugosa $\mathrm{H} 10$ & 2 & $\mathrm{~S}$ & 15.2 & 8.7 & 3.1 & 1.5 & 1 & $\mathrm{~S}$ \\
\hline C. guilliermondii MAT24 & 1 & $\mathrm{~S}$ & 6.5 & 5.5 & 4.1 & 1.7 & 1 & $\mathrm{~S}$ \\
\hline C. albicans $\mathrm{H} 38$ & 1 & $\mathrm{~S}$ & 7.4 & 6.1 & 3.1 & 0 & 1 & $\mathrm{~S}$ \\
\hline C. lusitaniae H50 & 1 & $\mathrm{~S}$ & 10.3 & 4.1 & 3.1 & 0 & 1 & $\mathrm{~S}$ \\
\hline
\end{tabular}

Percentage of cells with cylindrical intravacuolar structures (percent of cells with CIVS) after incubation with different concentrations of fluconazole (Flu for $120 \mathrm{~min}$ ). Data are mean of two independent experiments. No significant differences were found between the results of the two experiments. MICs were determined as described in Materials and methods. S, susceptible; R, resistant, S-DD, susceptible dose-dependent. 
azide added $30 \mathrm{~min}$ before incubation with fluconazole and analysis by FCM and by EFM [6].

\section{Viability counts}

Viable yeast cells in untreated (control) suspensions and in suspensions treated with the different concentrations of fluconazole or sodium azide for the indicated periods of time were enumerated by counting the number of cfu after plating out serial dilutions of each yeast suspension on Sabouraud agar plates. Colonies were counted after incubation for $24 \mathrm{~h}$ at $35^{\circ} \mathrm{C}$.

\section{Statistical analysis}

Student's $t$ test was used for statistical analysis; data were compared at a significance level of 0.05 .

\section{Results}

The fluconazole MIC values for the Candida isolates are shown in Table 1. Control strains showed MIC values within the expected range. Yeasts were considered susceptible (S) with an $\mathrm{MIC} \leqslant 8 \mathrm{mg} / \mathrm{L}$, resistant (R) with a $\mathrm{MIC} \geqslant 64 \mathrm{mg} / \mathrm{L}$ and susceptible dosedependent (S-DD) with a MIC ranging between 16 and $32 \mathrm{mg} / \mathrm{L} \mathrm{[5].}$

In yeasts exposed to $1 \mathrm{mM}$ sodium azide for $1 \mathrm{~h}$, the level of FUN-1 staining, as determined by FCM, was higher than in non-treated cells (Fig. 1) and no CIVS

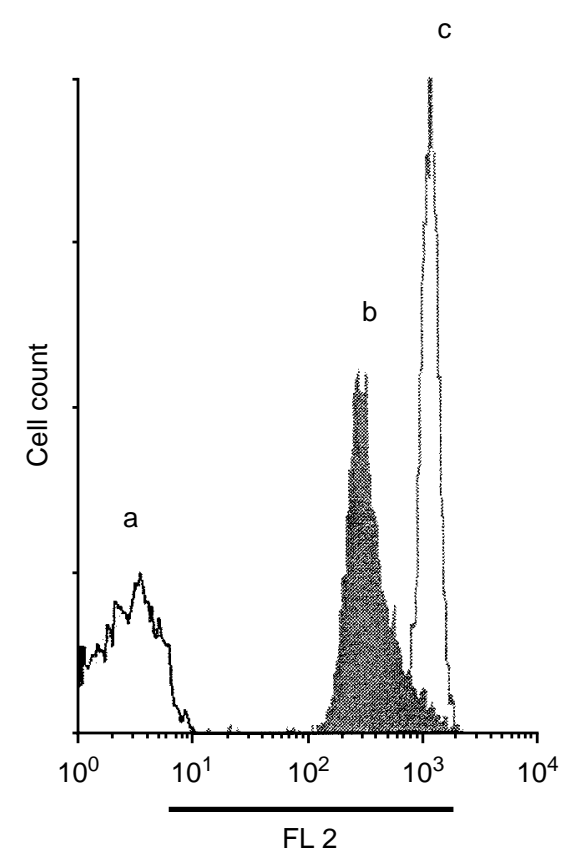

Fig. 1. Flow cytometry analysis of $C$. lusitaniae isolate H50 analysed at FL2, showing: (a) autofluorescence, (b) fluorescence of non-treated cells stained with FUN-1, (c) fluorescence of cells incubated with $1 \mathrm{mM}$ sodium azide for $1 \mathrm{~h}$ and stained with FUN-1. were seen by EFM (data not shown). As determined by cfu counts, yeast cells exposed to sodium azide under the above conditions were viable (data not shown). This confirmed that FUN-1 can be used to assess non-lethal metabolic impairment in yeast cells [4].

In the preliminary assay, a dose-dependent and timedependent increase in SI $(\mathrm{SI}>1)$ for the $\mathrm{S}$ strains was found by FCM (see isolate H50, Fig. 2), which was already evident after treatment with fluconazole for $30 \mathrm{~min}$ at the MIC. The S-DD isolate showed an SI $<1$ after $30 \mathrm{~min}$ of treatment with fluconazole at the MIC, but the SI increased to $>1$ after $60 \mathrm{~min}$ (see isolate M44, Fig. 2). With $\mathrm{R}$ isolates, an $\mathrm{SI}<1$ was found consistently, independent of duration of incubation (see isolate H58, Fig. 2) or fluconazole concentration (not shown).

Under EFM, a dose-dependent and time-dependent reduction of the percentage of cells with CIVS was found with the $\mathrm{S}$ strains (see isolate H50, Fig. 3). However, $120 \mathrm{~min}$ were needed to drop the percentage of cells with CIVS well below $50 \%$ of the control at the MIC. Regarding the S-DD strains, $120 \mathrm{~min}$ were also needed to reduce the percentage of cells with CIVS, but only slightly below $50 \%$ of the control at the $\mathrm{MIC}$, as shown in Fig. 3. In contrast, with $\mathrm{R}$ strains no noticeable reduction in the percentage of cells with CIVS was observed even after $120 \mathrm{~min}$ (see isolate H58, Fig. 3).

After treatment with fluconazole for $120 \mathrm{~min}$, at the concentrations used in both FCM and EFM assays, the yeasts remained viable as determined by cfu counts (data not shown).

The results obtained with the above selected isolates prompted the use of FUN-1 to test the activity of fluconazole on all the Candida isolates listed in Table

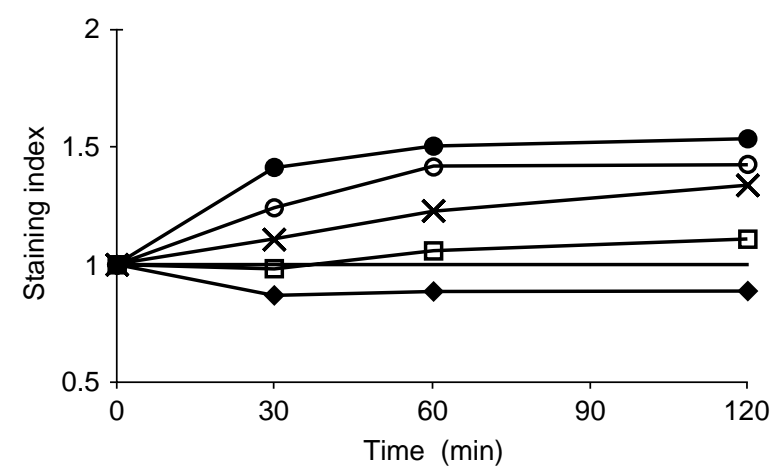

Fig. 2. Staining index of Candida isolates treated with different concentrations of fluconazole $(1-64 \mathrm{mg} / \mathrm{L})$, for different periods of time. $\diamond, \mathrm{H} 58,64 \mathrm{mg} / \mathrm{L} ; \square, \mathrm{M} 44$, $32 \mathrm{mg} / \mathrm{L} ; \times$, H50, $1 \mathrm{mg} / \mathrm{L} ; \mathrm{O}, \mathrm{H} 50,4 \mathrm{mg} / \mathrm{L} ; 0$, H50, $16 \mathrm{mg} / \mathrm{L}$. Staining index is defined as the ratio between the median intensity of fluorescence at FL2 of fluconazole-treated cells and of non-treated cells (control), both stained with FUN-1. 


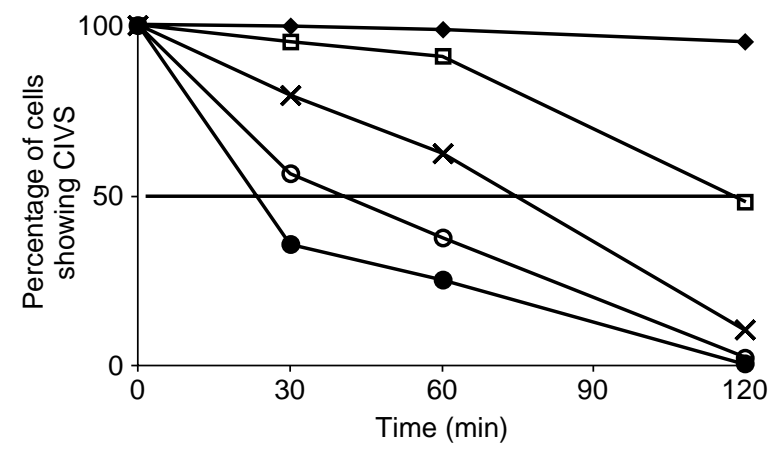

Fig. 3. Percentage of yeast cells with cylindrical intravacuolar structures (CIVS) after treatment with fluconazole at $1-64 \mathrm{mg} / \mathrm{L}$ for different periods of time, evaluated by epifluorescence microscopy after FUN-1 staining; 100\% represents the number of yeast cells with CIVS in cells not exposed to fluconazole (control): $\bullet, \mathrm{H} 58,64 \mathrm{mg} / \mathrm{L}$; $\square$, M44, $32 \mathrm{mg} / \mathrm{L} ; \times, H 50,1 \mathrm{mg} / \mathrm{L} ; \mathrm{O}, \mathrm{H} 50,4 \mathrm{mg} / \mathrm{L} ;$ $\mathrm{H} 50,16 \mathrm{mg} / \mathrm{L}$.

1, after treatment for $1 \mathrm{~h}$ in the case of FCM analysis and for $2 \mathrm{~h}$ with EFM.

FCM results with FUN-1 staining (Table 1) showed that, with fluconazole concentrations at or above the MIC (M27-A protocol), SI values were $<1.00$ in all $R$ isolates and $>1.00$ in all $\mathrm{S}$ isolates. Differences in SI values between $R$ and $S$ isolates were significant (see legend to Table 1). With S-DD isolates, significant differences in SI values were found in comparison with $\mathrm{R}$ isolates (but not with $\mathrm{S}$ isolates), with fluconazole concentrations of 16-32 mg/L (see legend to Table 1). Table 1 also shows that the pattern of susceptibility/ resistance to fluconazole correlated very well with the corresponding pattern determined according to the NCCLS M27-A protocol. Treatment with fluconazole for $2 \mathrm{~h}$ resulted in a marked reduction of the percentage of cells with CIVS, clearly below $50 \%$ of the control in all S or S-DD isolates (Table 2). Similar to the finding in the preliminary assay, a slight reduction below 50\% of the control was registered with the three S-DD isolates. Therefore, $50 \%$ of cells with CIVS was selected as the cut-off for the calculation of the MIC by EFM. No reduction of CIVS formation was noticed with $\mathrm{R}$ isolates (Table 2). Furthermore, under EFM the cytoplasm of $\mathrm{R}$ isolates showed a lower level of fluorescence in comparison with the control.

Sanglard et al. reported that exposure to $0.1 \mathrm{mM}$ sodium azide for $30 \mathrm{~min}$ blocked drug efflux systems [6]. This procedure did not affect either FUN-1 processing or viability of all Candida isolates tested in the assays in the present study, as confirmed by the evaluation of CIVS formation under EFM and by cfu counts, respectively (data not shown). When yeast cells were treated with fluconazole after pre-incubation with sodium azide (under the above conditions), all $\mathrm{R}$ and $\mathrm{S}$ DD isolates, with the exception of C. krusei strains, showed decreased MIC values for the antifungal agent as determined by the M27-A protocol, changing the phenotype to $\mathrm{S}$ (Table 3 ). A corresponding increase in intensity of fluorescence at FL2 (SI >1.00) determined by FCM (Fig. 4) was registered, indicating an increased intracellular diffuse accumulation of FUN-1, again with the exception of C. krusei (data not shown). Also, a decrease in the percentage of the cells with CIVS was seen in all the isolates with the exception of C. krusei. Thus, these modifications resulted in decreased MIC values determined by FCM or EFM for all resistant isolates except C. krusei (Table 3). The MIC and susceptibility phenotype of cells pre-treated with azide determined by FCM and EFM again correlated very well with those determined with the M27-A protocol (Table 3).

\section{Discussion}

The objective of the present study was to develop rapid fluorescence techniques for susceptibility testing of Candida clinical isolates to fluconazole. For this purpose, the pattern of susceptibility was determined

Table 3. MIC values $(\mathrm{mg} / \mathrm{L})$ and phenotypes determined by the M27-A protocol, and by epifluorescence microscopy (EFM) and flow cytometry (FCM) by staining with FUN-1, after pre-incubation with $0.1 \mathrm{mM}$ sodium azide $\left(\mathrm{NaN}_{3}\right)$ for $30 \mathrm{~min}$

\begin{tabular}{|c|c|c|c|c|c|c|}
\hline Isolate & $\begin{array}{l}\text { MIC M27-A } \\
\qquad\left(\mathrm{NaN}_{3}\right)\end{array}$ & $\begin{array}{l}\text { Phenotype M27-A } \\
\left(\mathrm{NaN}_{3}\right)\end{array}$ & MIC FCM & $\begin{array}{l}\text { Phenotype FCM } \\
\left(\mathrm{NaN}_{3}\right)\end{array}$ & $\begin{array}{l}\text { MIC EFM } \\
\left(\mathrm{NaN}_{3}\right)\end{array}$ & $\begin{array}{c}\text { Phenotype EFM } \\
\left(\mathrm{NaN}_{3}\right)\end{array}$ \\
\hline C. krusei $\mathrm{H} 29$ & $>64$ & $\mathrm{R}$ & $>32$ & $\mathrm{R}$ & $>32$ & $\mathrm{R}$ \\
\hline C. krusei $\mathrm{H} 32$ & $>64$ & $\mathrm{R}$ & $>32$ & $\mathrm{R}$ & $>32$ & $\mathrm{R}$ \\
\hline C. krusei $\mathrm{H} 11$ & $>64$ & $\mathrm{R}$ & $>32$ & $\mathrm{R}$ & $>32$ & $\mathrm{R}$ \\
\hline C. krusei H9 & $>64$ & $\mathrm{R}$ & $>32$ & $\mathrm{R}$ & $>32$ & $\mathrm{R}$ \\
\hline C. albicans M36 & 0.5 & $\mathrm{~S}$ & 1 & $\mathrm{~S}$ & 1 & $\mathrm{~S}$ \\
\hline C. albicans H37 & 0.5 & $\mathrm{~S}$ & 4 & $\mathrm{~S}$ & 4 & $\mathrm{~S}$ \\
\hline C. albicans $\mathrm{H} 65$ & 2 & S & 1 & $\mathrm{~S}$ & 4 & $\mathrm{~S}$ \\
\hline C. albicans H66 & 8 & $\mathrm{~S}$ & 1 & $\mathrm{~S}$ & 4 & $\mathrm{~S}$ \\
\hline C. albicans H58 & 1 & $\mathrm{~S}$ & 1 & $\mathrm{~S}$ & 1 & $\mathrm{~S}$ \\
\hline C. glabrata $\mathrm{H} 30$ & 4 & S & 1 & $\mathrm{~S}$ & 4 & $\mathrm{~S}$ \\
\hline C. glabrata M2 & 0.25 & S & 1 & $\mathrm{~S}$ & 1 & $\mathrm{~S}$ \\
\hline C. albicans SER5 & 0.5 & $\mathrm{~S}$ & 4 & $\mathrm{~S}$ & 4 & $\mathrm{~S}$ \\
\hline C. albicans M44 & 0.25 & $\mathrm{~S}$ & 1 & $\mathrm{~S}$ & 1 & $\mathrm{~S}$ \\
\hline
\end{tabular}

MICs were determined as described in Materials and methods. S, susceptible; R, resistant; S-DD, susceptible dose-dependent. 
A

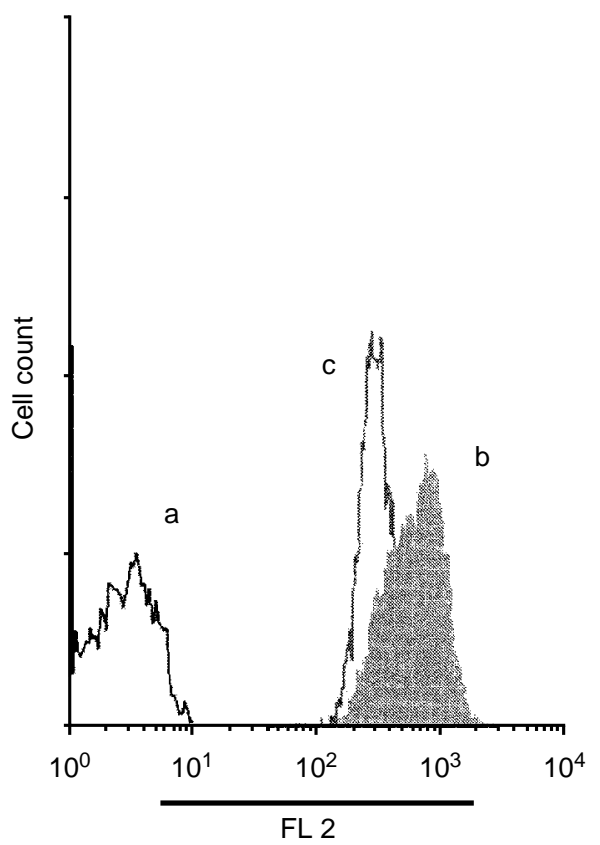

B

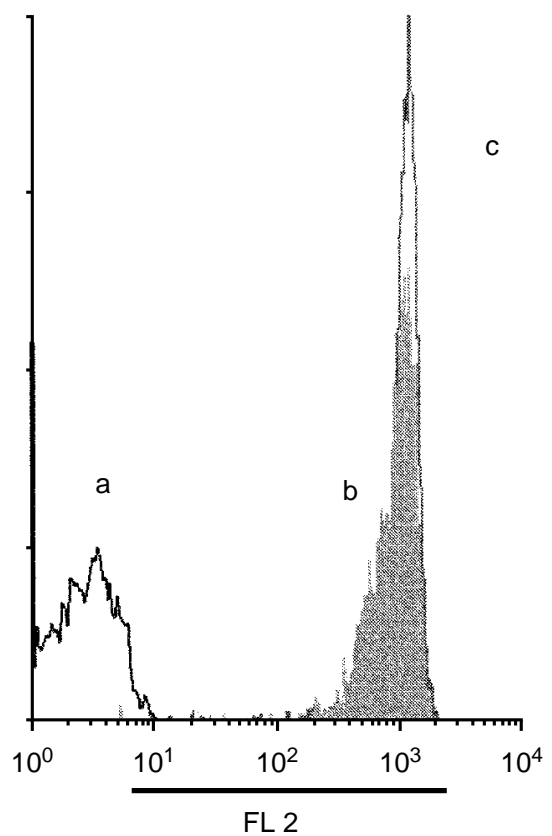

Fig. 4. Histograms determined by flow cytometry analysis at FL2 of isolate H65 (resistant to fluconazole). (A) a, autofluorescence; b, fluorescence of non-treated cells stained with FUN-1; c, fluorescence of cells treated with fluconazole $32 \mathrm{mg} / \mathrm{L} 1 \mathrm{~h}$ and stained with FUN-1. (B) a, autofluorescence; b, fluorescence of cells pre-incubated with $0.1 \mathrm{mM}$ sodium azide for $30 \mathrm{~min}$, non-treated with fluconazole and stained with FUN-1; c, fluorescence of cells preincubated with sodium azide as above, followed by treatment with fluconazole $8 \mathrm{mg} / \mathrm{L}$ for $1 \mathrm{~h}$ and stained with FUN-1.

by detecting early metabolic changes produced by fluconazole by means of FUN-1 staining followed by FCM or EFM.

Susceptibility testing according to the NCCLS M27-A protocol [5] is time-consuming and presents serious drawbacks in endpoint determination. Another disadvantage arises from the fact that the M27-A protocol does not provide rapid information regarding changes in cell metabolic capacity induced by fungistatic drugs or on the mechanisms involved in antifungal resistance. One of the main advantages of the use of FCM in antifungal testing, compared with the NCCLS M27-A protocol, is that it offers the possibility of an extremely fast multiparametric 'cell by cell' analysis, performed on a very large cell population. The comparatively short testing time required for the analysis and the ability to sort cells adds to the attractiveness of the method [7-9]. Both FCM and EFM with different fluorescent probes have been used in improved assays for susceptibility testing [10] and the development of optimised protocols with such probes has allowed preliminary studies of susceptibility of Candida strains to antifungal agents [11-15].

FUN-1 is a recently developed probe that after its uptake by the yeast cell is accumulated in the cytoplasm, being converted only by metabolically active yeast cells from the diffuse cytosolic pool with a green-yellow fluorescence to red intravacuolar structures (CIVS) [4].
Excessive loading of FUN-1 increases the amount of residual green fluorescence, because at high fluorochrome concentrations the metabolic capacity of the Candida cell may be exceeded and, consequently, FUN-1 will stain viable cells non-specifically. On the other hand, sub-optimal loading typically limits both the number, size and brightness of CIVS [4].

After assaying serial concentrations of FUN-1 and of yeast cells, $0.5 \mu \mathrm{M} / 10^{6}$ cells was found to be the most suitable concentration for FCM analysis (unpublished observations). The use of a 10 -fold greater concentration of FUN-1 by Wenisch et al. [15] may well explain the discrepancy between the results of the present study and their findings. For EFM analysis the use of $1 \mu \mathrm{M} / 10^{6}$ cells resulted in bigger CIVS, making the observation easier.

Sodium azide (1 mM) was used as a control for FUN-1 staining because at this concentration the yeast respiratory metabolism is inhibited, rendering the cells unable to process the probe [4]. The intensity of fluorescence at FL2 of azide-treated cells was significantly higher than that of non-treated cells, corresponding to an SI $>1.00$. Accordingly, yeast cells susceptible to fluconazole showed an SI $>1.00$ after treatment with the antifungal agent for $1 \mathrm{~h}$, indicating a serious impairment of yeast metabolism.

An excellent correlation was found between the MIC determined by FCM with FUN-1 staining and the 
corresponding value determined according to the conventional M27-A protocol, the susceptibility/resistance phenotype being identical for both methods in all isolates tested.

In concordance with the results of FCM, EFM revealed that a significant number of cells in a population of Candida $\mathrm{S}$ strains became clearly unable to process FUN-1 into CIVS after exposure to active concentrations of fluconazole, whereas in $\mathrm{R}$ strains the probe was processed similarly to untreated yeast cells (control). The good correlation between results obtained with EFM and those obtained with the M27-A protocol suggests that both EFM and FCM could be used as alternative methods to determine the susceptibility pattern of Candida isolates to fluconazole. However, compared with FCM, EFM is more time-consuming, requires considerable experience, is observer-dependent and analyses a much smaller number of cells, which may considerably affect the objectivity and sensitivity of the method. However, EFM may represent an alternative for those laboratories that do not have access to a flow cytometer, but possess an epifluorescence microscope.

FCM provides a very reliable and fast method to determine the susceptibility/resistance phenotype to fluconazole. In fact, after primary isolation of a yeast, the time needed for antifungal testing (including preparation and reading) will be $c \cdot 1.5-2 \mathrm{~h}$ for FCM and 3-3.5 $\mathrm{h}$ for EFM, in comparison with at least $48 \mathrm{~h}$ in the case of MIC determination according to the NCCLS M27-A protocol.

While S strains showed an SI $>1$ after treatment with active concentrations of fluconazole by FCM, in R strains a decrease in green-yellow fluorescence (i.e., a $\mathrm{SI}<1$ ) was found, although these $\mathrm{R}$ strains processed the probe with the production of CIVS. EFM confirmed this FCM observation, by showing that $\mathrm{R}$ strains were less fluorescent than the control after exposure to fluconazole and FUN-1 staining. The decreased SI in the $\mathrm{R}$ strains in comparison with the control could be explained by the transport of the probe out of the cell by the activity of efflux pumps. In fact, one of the most common mechanisms of drug resistance in yeast cells involves active transporters that pump drugs out of the cells, thereby reducing their cytotoxicity $[1,16]$. Sanglard et al. [6] showed that less $\left[{ }^{3} \mathrm{H}\right]$ fluconazole is found within $\mathrm{R}$ strains than in $\mathrm{S}$ strains and that the intracellular content of $\left[{ }^{3} \mathrm{H}\right]$ fluconazole increased when the resistant strains were pre-incubated with $0.1 \mathrm{mM}$ sodium azide, indicating that the resistance to fluconazole could be mediated by energy-dependent efflux pumps. To test the possibility of involvement of efflux pumps in the resistance of the study isolates to fluconazole, they were incubated with $0.1 \mathrm{mM}$ sodium azide before treatment with the antifungal agent. Neither viability nor FUN-1 processing were altered by this pre-treatment in any of the isolates in the study panel. The decrease in MIC values (determined both by cytometric methods and by protocol M27-A) after preincubation with $0.1 \mathrm{mM}$ sodium azide agrees with the interpretation that fluconazole efflux might be overexpressed in $\mathrm{R}$ strains. The concomitant reversion of SI values from $\mathrm{SI}<1$ to $\mathrm{SI}>1$ after pre-treatment with sodium azide suggests that FUN-1 may well be transported out of the cells by the same carrier that transports the antifungal agent. The observation under EFM in $\mathrm{R}$ isolates (apart from CIVS formation) of a lower cytoplasmic fluorescence than the control helped in the interpretation of FCM results (decrease of SI) and further supports the occurrence of efflux of FUN-1. The demonstration of efflux of probes like rhodamine $1,2,3$, calcein-AM and $\mathrm{DIOC}_{5}$, concomitantly with fluconazole $[17,18]$, supports the non-specificity of the transport mediated by efflux pumps. Thus, FUN-1 is possibly another probe that might be useful to demonstrate energy-dependent drug transporters conferring resistance.

The reduction of MIC after pre-incubation with $0.1 \mathrm{mM}$ sodium azide was found with all resistant Candida isolates with the exception of $C$. krusei strains. $C$. krusei is known to be intrinsically resistant to fluconazole [19], possibly by mechanisms other than that involving ATP-dependent efflux pumps. The presence in C. krusei of alternative metabolic pathways to obtain energy is another possibility that has to be considered.

In conclusion, these results show that FCM and EFM methods, after FUN-1 staining, can be used as a reliable and rapid assay for the assessment of susceptibility of Candida clinical isolates to fluconazole.

We thank Manuel T. Silva for helpful support, Cecília Leão and Manuela Corte-Real for reviewing the manuscript, and Clara Coelho and Alexandre Salvador for excellent technical assistance. This work was supported by Praxis XXI grant PSAU/C/SAU/0014/96 (Fundação para a Ciência e Tecnologia, Lisboa, Portugal) and Comissão de Fomento da Investigação em Cuidados de Saúde-Ministério da Saúde, project no. 83/99.

\section{References}

1. White TC, Marr KA, Bowden RA. Clinical, cellular, and molecular factors that contribute to antifungal drug resistance. Clin Microbiol Rev 1998; 11: 382-402.

2. Ghannoum MA, Rex JH, Galgiani JN. Susceptibility testing of fungi: current status of correlation of in vitro data with clinical outcome. J Clin Microbiol 1996; 34: 489-495.

3. Sheehan DJ, Hitchcock CA, Sibley CM. Current and emerging azole antifungal agents. Clin Microbiol Rev 1999; 12: 40-79.

4. Millard PJ, Roth BL, Thi H-PT, Yue ST, Haugland RP Development of the FUN-1 family of fluorescent probes for vacuole labeling and viability testing of yeasts. Appl Environ Microbiol 1997; 63: 2897-2905.

5. National Committee for Clinical Laboratory Standards. Reference method for broth dilution antifungal susceptibility testing of yeasts. Approved standard M27-A. Wayne, PA, NCCLS. 1997.

6. Sanglard D, Kuchler K, Ischer F, Pagani J-L, Monod M, Bille J. Mechanisms of resistance to azole antifungal agents in 
Candida albicans isolates from isolates from AIDS patients involve specific multidrug transporters. Antimicrob Agents Chemother 1995; 39: 2378-2386.

7. Pore RS. Antibiotic susceptibility testing of Candida albicans by flow cytometry. Curr Microbiol 1990; 20: 323-328.

8. Davey HM, Kell DB. Flow cytometry and cell sorting of heterogeneous microbial populations: the importance of singlecell analyses. Microbiol Rev 1996; 60: 641-696.

9. Lynch ME, Kukuruga M, Nakeff A, Fidel PL, Sobel JD. Flow cytometric analysis of germ tube in Candida albicans. J Med Vet Mycol 1993; 31: 367-376.

10. Laerum OD, Farsund T. Clinical application of flow cytometry: a review. Cytometry 1981; 2: 1-13.

11. Ramani R, Ramani A, Wong SJ. Rapid flow cytometric susceptibility testing of Candida albicans. J Clin Microbiol 1997; 35: 2320-2324.

12. Durodie J, Coleman K, Simpson IN, Loughbourgh $\mathrm{SH}$ Winstanley DW. Rapid detection of antimicrobial activity using flow cytometry. Cytometry 1995; 21: 374-377.

13. Pina-Vaz C, Sansonetty F, Rodrigues AG, Martinez-de-Oliveira J, Fonseca AF, Mårdh P-A. Antifungal activity of ibuprofen alone and in combination with fluconazole against Candida species. J Med Microbiol 2000; 49: 831-840.

14. Pina-Vaz C, Rodrigues AG, Sansonetty F, Martinez-de-Oliveira $\mathrm{J}$, Fonseca AF, Mårdh P-A. Antifungal activity of local anesthetics against Candida species. Infect Dis Obstet Gynecol 2000; 8: 124-137.

15. Wenisch C, Linnau KF, Parschalk B, Zedtwitz-Liebenstein K, Georgopoulos A. Rapid susceptibility testing of fungi by flow cytometry using vital staining. J Clin Microbiol 1997; 35: 510.

16. Albertson GD, Niimi M, Cannon RD, Jenkinson HF. Multiple efflux mechanisms are involved in Candida albicans fluconazole resistance. Antimicrob Agents Chemother 1996; 40: 28352841.

17. Clark FS, Parkinson T, Hitchcock CA, Gow NAR. Correlation between rhodamine 123 accumulation and azole sensitivity in Candida species; possible role for drug efflux in drug resistance. Antimicrob Agents Chemother 1996; 40: 419-425.

18. Prudêncio C, Sansonetty F, Sousa MJ, Côrte-Real M, Leão C Rapid detection of efflux pumps and their relation with drug resistance in yeast cells. Cytometry 2000; 39: 26-35.

19. Marichal P, Vanden Bossche H. Mechanisms of resistance to azole antifungals. Acta Biochim Pol 1995; 42: 509-516. 